\title{
Total Bacterial Load within Echinacea purpurea, Determined Using a New PCR-based Quantification Method, is Correlated with LPS Levels and In Vitro Macrophage Activity
}

\author{
Authors \\ Nirmal D. Pugh ${ }^{1,2}$, Colin R. Jackson ${ }^{3}$, David S. Pasco ${ }^{1,2,4}$ \\ Affiliations \\ National Center for Natural Products Research, University of Mississippi, University, MS, USA \\ 2 Research Institute of Pharmaceutical Sciences, University of Mississippi, University, MS, USA \\ ${ }^{3}$ Department of Biology, University of Mississippi, University, MS, USA \\ ${ }^{4}$ Department of Pharmacognosy, University of Mississippi, University, MS, USA
}

Key words

- Echinacea purpurea

- Asteraceae

- macrophage activation

- lipopolysaccharide

- bacteria

- bacterial load

- PCR method

\section{received May 7, 2012}

revised October 8, 2012

accepted October 29, 2012

Bibliography

DOI http://dx.doi.org/

10.1055/s-0032-1328023

Published online December 4,

2012

Planta Med 2013; 79: 9-14

(c) Georg Thieme Verlag KG

Stuttgart · New York .

ISSN 0032-0943

\section{Correspondence}

David S. Pasco, Ph.D.

National Center for Natural

Products Research

School of Pharmacy

University of Mississippi

University, MS 38677-1848

USA

Phone: + 16629157130

Fax: + 16629157062

dpasco@olemiss.edu

\section{Abstract}

$\nabla$

Our previous studies indicate that the majority of in vitro monocyte/macrophage activation exhibited by extracts of Echinacea depends on bacterial components. In the present study, total bacterial load was determined within E. purpurea samples and ranged from $6.4 \times 10^{6}$ to $3.3 \times 10^{8}$ bacteria/g of dry plant material. To estimate total bacterial load, we developed a PCR-based quantification method that circumvents the problems associated with nonviable/nonculturable cells (which pre-

\section{Introduction}

Clinical trials testing Echinacea's (Asteraceae) potential for preventing and/or treating the common cold are difficult to interpret because they have used a wide variety of chemically ill-defined preparations. A review [1] of clinical trials using Echinacea found that while many studies have reported some benefit in the treatment of common colds, others have failed to show any efficacy. At present, one of the most problematic factors for conducting such trials is in the selection of Echinacea material or extract type. This is due to the incomplete identification of therapeutically relevant components that would be used to standardize these products. In addition, despite decades of research, it is not known if Echinacea's main therapeutic action on colds and the flu is immunostimulatory, anti-inflammatory, or a combination of both. In vitro [2-4] and animal research [5-7] indicates that this botanical exerts both therapeutic actions, and Echinacea alkylamides represent the major anti-inflammatory component. With respect to the immune-enhancing potential of Echinacea, our research [8] suggests that bacterial Braun-type lipoproteins and lipopolysaccharides (LPS) were responsible for over $97 \%$ of the in vitro macrophage activation exhibited by extracts of cludes using plate counts) or the coamplification of mitochondrial or chloroplast DNA with the use of universal bacterial primers (which precludes the use of qPCR). Differences in total bacterial load within Echinacea samples were strongly correlated with the activity (NF-kB activation in THP-1 cells) and content of bacterial lipopolysaccharides within extracts of this plant material. These results add to the growing body of evidence that bacteria within Echinacea are the main source of components responsible for enhancing innate immune function.
Echinacea and seven other botanicals traditionally used to enhance immune function. The contribution of bacterial components within extracts to macrophage activation was assessed using agents that targeted bacterial Braun-type lipoproteins (lipoprotein lipase) and LPS (polymyxin B). These biochemical approaches were also used to determine that variations in the content of these two bacterial components were responsible for the up to a 200 -fold difference in in vitro macrophage/monocyte activation potential exhibited by commercially diverse E. purpurea and E. angustifolia bulk material obtained from six North American suppliers [4]. It is our hypothesis that differences in bacterial content and/or bacterial type are responsible for the substantial variation in the innate immune-enhancing activity exhibited by this botanical.

The objective of the present study was to directly assess total bacterial load within E. purpurea root and herb (aerial) samples, and to determine if differences in bacterial load correlate with in vitro macrophage activity of the plant material. To estimate the total bacterial load, we developed a PCRbased quantification method that circumvents the problems associated with nonviable/nonculturable cells (which precludes using plate counts) or the coamplification of plant mitochondrial or 
chloroplast DNA with the use of universal bacterial primers (which precludes the use of qPCR).

\section{Materials and Methods \\ $\nabla$}

\section{Echinacea purpurea (L.) Moench plant material}

Bulk root and herb (aerial) material for E. purpurea were obtained from the following six commercial suppliers: Frontier Natural Products Co-op, lot number 50811.2331, Gaia Herbs, lot numbers 00033874 and 00033507, Glenbrook Farms Herbs \& Such, lot numbers not available, Mountain Rose Herbs, lot numbers 11987 and 12066, Richters, lot numbers 21283 and 21580, and Trout Lake Farm LLC, lot numbers EPR-K6041-BCP and EPHS2051-E3P.

Individual plants of $E$. purpurea were cultivated at the University of Mississippi. Root and herb parts were harvested by washing extensively to remove soil and then immediately freeze-dried to prevent postharvest growth or introduction of bacteria.

Voucher specimens for all E. purpurea plant samples were deposited in the NCNPR repository at the University of Mississippi (voucher numbers NP1019, NP1048, NP2001-NP2006, NP2008NP2012).

\section{Alfalfa sprout germination and ampicillin treatment}

Organic alfalfa (Medicago sativa L., Fabaceae) seeds (Johnny's Selected Seeds, lot \#25089) were surface sterilized by soaking in $10 \%$ chlorox $/ 0.1 \%$ Tween-20 for 12 min followed by four rinses with sterile water. One hundred seeds were then transferred to each of two flasks containing either $10 \mathrm{~mL}$ sterile water alone or $10 \mathrm{~mL}$ sterile water containing ampicillin $(30 \mu \mathrm{g} / \mathrm{mL})$. Seeds were aseptically germinated for 7 days at ambient temperature under natural light and, on days 2, 4, and 6, treatment solutions were replaced with fresh solutions. Sprouts were freeze-dried after removal of hulls and unsprouted seeds.

\section{Extraction of plant material for analysis of activity and content of LPS}

Finely ground plant material (50 mg for E. purpurea samples or $20 \mathrm{mg}$ for alfalfa samples) was extracted four times with $95 \%$ ethanol $\left(1.0-1.5 \mathrm{~mL}\right.$ fresh solvent added and incubated at $75^{\circ} \mathrm{C}$ for 30-45 minutes for each extraction) to remove anti-inflammatory components. Ethanol extracted plant material was dried at $50-55^{\circ} \mathrm{C}$ and then extracted with $0.5 \mathrm{~mL}$ of water containing $4 \%$ SDS at $98^{\circ} \mathrm{C}$ for 1 hour. Following removal of SDS using SDS-out reagent (Pierce) in the presence of $1 \%$ octylglucoside, crude extracts were assessed for activity and endotoxin levels.

\section{Monocyte activation assay and limulus amebocyte lysate (LAL) assay}

The THP-1 human monocyte cell line (American Type Culture Collection) was transfected with a luciferase reporter gene construct containing two copies of NF-KB motif from HIV/IgK, and samples were evaluated as described previously [9]. Monocyte activation exhibited by Echinacea extracts is reported as an $\mathrm{EC}_{50}$ value that represents the concentration of plant material $(\mu \mathrm{g} / \mathrm{mL})$ required to activate cells to $50 \%$ of maximal activation of NF-KB by LPS $(10 \mu \mathrm{g} / \mathrm{mL}$, E. coli, serotype 026:B6; Sigma).

The amount of LPS (bacterial endotoxin) in the extracts was determined using a limulus amebocyte lysate (LAL) assay [Chromo-LAL test kit with Glucashield ${ }^{\circledR}(1 \rightarrow 3)-\beta$-D-Glucan Inhibiting Buffer] from Associates of Cape Cod, Inc. Data is reported as endo- toxin units (EU) per g of dried plant and represents the average of duplicate determinations.

\section{Determination of plant total bacterial load}

DNA was extracted from a known mass (100 mg for E. purpurea samples or $20 \mathrm{mg}$ for alfalfa samples) of ground plant material using PowerSoil DNA isolation kits (Mo Bio), followed by a clean-up procedure (PowerClean; Mo Bio) to remove potential PCR inhibitors. A portion of the bacterial 16S rRNA gene was amplified from each purified sample using the primer pair $799 \mathrm{f}\left(5^{\prime}-\right.$ AACMGGATTAGATACCCKG-3') and $1492 \mathrm{r}$ (5'-GGTTACCTTGTTACGACTT-3') described by Chelius and Triplett [10]. These primers exclude the coamplification of chloroplast DNA, and potentially yield a bacterial product (approximately $735 \mathrm{bp}$ ) and a larger (1090 bp) mitochondrial product when used to amplify DNA extracted from the plant material [10]. Amplifications occurred in $50 \mu \mathrm{L}$ reactions comprised of a $2 \mathrm{mM} \mathrm{MgCl}_{2}$ PCR buffer, $0.2 \mathrm{mM}$ deoxyribonucleoside triphosphates, $0.4 \mu \mathrm{M}$ of each primer, 1.0 U Taq polymerase, as well as $2 \mu \mathrm{L}$ of sample DNA. Reactions consisted of $3 \mathrm{~min}$ at $95^{\circ} \mathrm{C}$, followed by 30 cycles of $94^{\circ} \mathrm{C}$ (20 s), $50^{\circ} \mathrm{C}(40 \mathrm{~s}), 72^{\circ} \mathrm{C}(40 \mathrm{~s})$, and a final extension of $72{ }^{\circ} \mathrm{C}$ (7 min). Amplification products $(5 \mu \mathrm{L})$ were visualized on $1.2 \%$ agarose gels and the intensity of the bacterial band was determined using a Kodak Gel Logic 200 imaging system running Molecular Imaging Software 4.0 (Eastman Kodak).

A strain of Pseudomonas (NPC16) that we have previously isolated from freshly harvested E. purpurea (data not shown) was used as a reference bacterium to relate band intensity to bacterial load. Pseudomonas NPC16 was cultured in trypticase soy broth at $22^{\circ} \mathrm{C}$ and a sample was taken after $20 \mathrm{~h}$ (a time determined by plate counts to correspond to the late exponential phase). The sample was serially diluted, and the bacterial load in the culture was determined as the viable count in cells/mL. A second $20-\mathrm{h}$ sample was taken, serially diluted, and each dilution centrifuged (6000 g, $10 \mathrm{~min}$ ) to pellet cells, and the pellets were frozen for later DNA extraction. Results from the viable count allowed us to determine the bacterial load in each of these cell pellets, which ranged from $1.0 \times 10^{2}$ to $1.0 \times 10^{9}$ cells. DNA was extracted and amplified from each pellet using the same procedure as for the plant material. Intensity of each of the resulting amplification products in agarose gels was similarly determined to develop a standard curve-relating band intensity to bacterial load in cells.

\section{Statistics}

Simple linear regressions were used to relate bacterial load to PCR product band intensity for the standard curve samples. These regressions were then used to determine bacterial load in plant extracts based on their PCR product band intensity. Relationships between bacterial load, monocyte activation (as $\mathrm{EC}_{50}$ ), and the amount of LPS (endotoxin) in E. purpurea samples were examined by pairwise linear regressions. Because the values for each variable spanned a range of $2-5$ orders of magnitude and were not normally distributed, data for each variable were $\log _{10}$ transformed prior to regressions [11]. All transformations and regressions were conducted in Microsoft Excel 2007.

\section{Results}

$\nabla$

Using molecular methods (PCR, qPCR) to estimate total bacterial cell load is problematic since the use of universal 16S ribosomal bacterial primers is complicated by the coamplification of chloro- 


\section{a

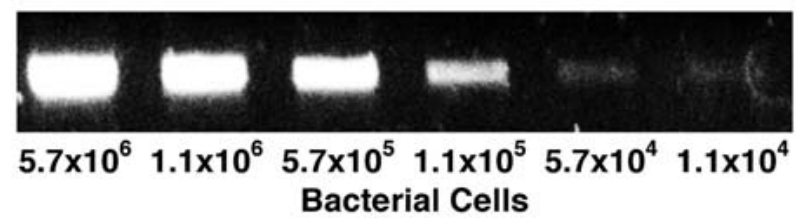

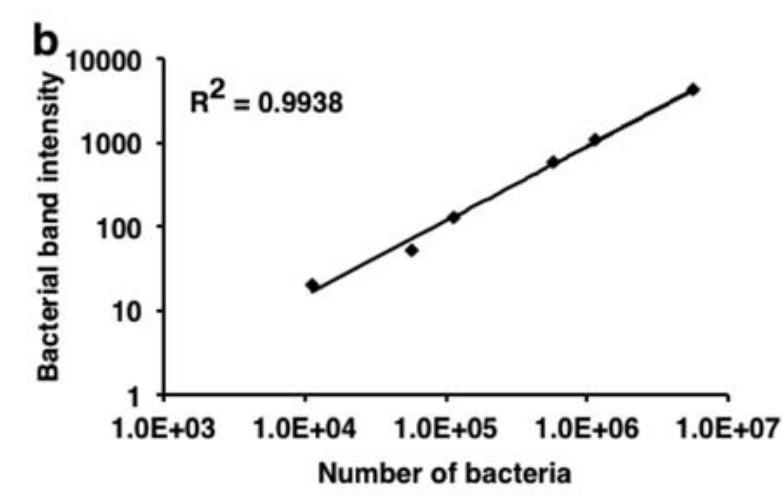

C

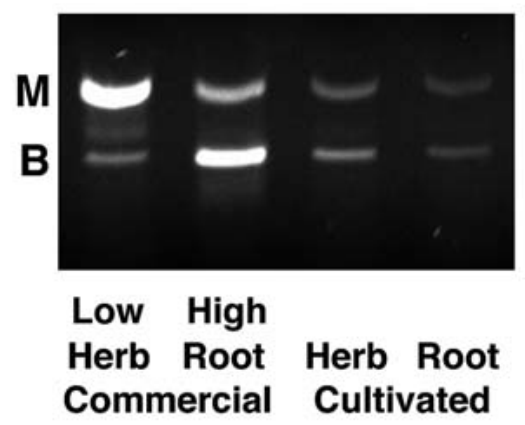

Fig. 1 An example illustrating bacterial load determination in dried Echinacea plant samples. A representative standard curve is presented in a and b. DNA was extracted from six known quantities of a bacterial isolate (Pseudomonas NPC16) and amplified with bacterial 165 rDNA primers; PCR products were visualized on an agarose gel (a). Band intensities were quantified ( $\log _{10}, y$-axis) and plotted against a known bacterial number ( $\log _{10}, x$-axis) (b). c E. purpurea root and herb (aerial) plant parts were obtained as bulk raw material from commercial growers and an individual plant cultivated at the University of Mississippi. "Low" and "High" indicates activity of extracts from commercial plant material as measured by NF-KB activation in THP-1 cells. DNA was extracted from dried plant material and amplified with bacterial 165 rDNA primers. PCR products are visualized after separation of bacterial bands "B" from mitochondrial bands " $M$ " on an agarose gel.

plast and mitochondrial DNA. To overcome this problem, we used bacterial $16 \mathrm{~S}$ rDNA primers that do not amplify chloroplast DNA [10] to develop a PCR-based quantification method. DNA is extracted from dried $E$. purpurea plant material, followed by a secondary sample clean-up step. The clean-up step is necessary to remove plant components such as polyphenols, polysaccharides, and humic substances that interfere with DNA amplification (data not shown). Bacterial PCR products (735 bp) are separated from mitochondrial products (1090 bp) on agarose gels and the intensity of the bacterial band is then compared to band intensities of a standard curve generated using PCR products from known bacterial numbers. $\mathbf{F i g .} \mathbf{1} \mathbf{a}$ and $\mathbf{b}$ provide a representa- tive standard curve illustrating linearity $\left(R^{2}=0.9938\right)$ between $1.1 \times 10^{4}$ and $5.7 \times 10^{6}$ bacterial cells (concentration range of over two orders of magnitude). 0 Fig. 1 c shows an example that demonstrates the usefulness of this method to determine differences in total bacterial load between bulk commercial E. purpurea plant samples that exhibit "low" and "high" monocyte stimulatory activity. An example is also provided that illustrates detection of total bacterial load in E. purpurea herb (aerial) and root samples from plant material cultivated at the University of Mississippi. These plant parts were freshly harvested, extensively washed to remove soil and surface bacteria, and then immediately freezedried to prevent postharvest growth or introduction of bacteria. To allow accurate detection of monocyte stimulatory components, the plant material was first extracted four times with 95\% ethanol to remove alkylamides and other anti-inflammatory substances that are inhibitors of monocyte activation. Ethanol extracted plant material was then further extracted with $4 \%$ SDS $\left(98^{\circ} \mathrm{C}, 1 \mathrm{~h}\right)$ to obtain the immune-enhancing components. E. purpurea root and herb (aerial) bulk commercial plant material used in our previous study [4] was also included in this research since they exhibit a wide range of in vitro monocyte/macrophage activity. The total bacterial load in plant samples was estimated using the PCR-based quantification method described above, and levels ranged from $6.4 \times 10^{6}$ to $3.3 \times 10^{8}$ bacteria/g of dry plant material. The results presented in $\odot$ Fig. 2 a show that the activity (NF-кB activation in THP-1 cells) exhibited by Echinacea extracts was correlated with the total load of bacterial cells in this plant material $\left(R^{2}=0.54, p=0.004\right)$. Likewise, 0 Fig. $2 b$ demonstrates that the content of LPS as determined by the LAL assay was also correlated with the total bacterial load $\left(R^{2}=0.53, p=0.005\right)$. In support of our previous research [4], - Fig. $2 \mathrm{c}$ shows that there is a very strong dependence of monocyte stimulatory activity on LPS concentration in E. purpurea plant extracts $\left(R^{2}=0.88, p=\right.$ 0.000003 ).

We have previously used $[7,8]$ alfalfa sprouts as a model system since extracts of this plant material exhibit high monocyte stimulatory activity and germination/harvest conditions are easily controllable. High levels of activity are observed in extracts of sprouts germinated under aseptic conditions using surface sterilized seeds and the appearance of this activity is suppressed by treatment with ampicillin and other antibiotics [8]. The results presented in $\bullet$ Fig. 3 provide further evidence that the activity detected in this system is of bacterial origin. In agreement with our previous research [8], extracts from sprouts grown in the presence of ampicillin for seven days exhibited undetectable activity at all concentrations tested as compared to control sprouts. - Fig. 3 insert shows that ampicillin treatment also substantially suppresses total bacterial load during the germination of alfalfa seeds. Total bacterial load estimates in cells/g dry weight of control sprouts versus ampicillin-treated sprouts were $7.7 \times 10^{8}$ and $6.3 \times 10^{6}$, respectively (a difference of 122 -fold). The content of LPS was undetectable in both control sprouts and ampicillintreated sprouts. Since only gram-negative bacteria produce LPS, this result suggests that most of the bacteria present were grampositive. Ampicillin treatment did not influence the final biomass or outward appearance of the sprouts (data not shown). 

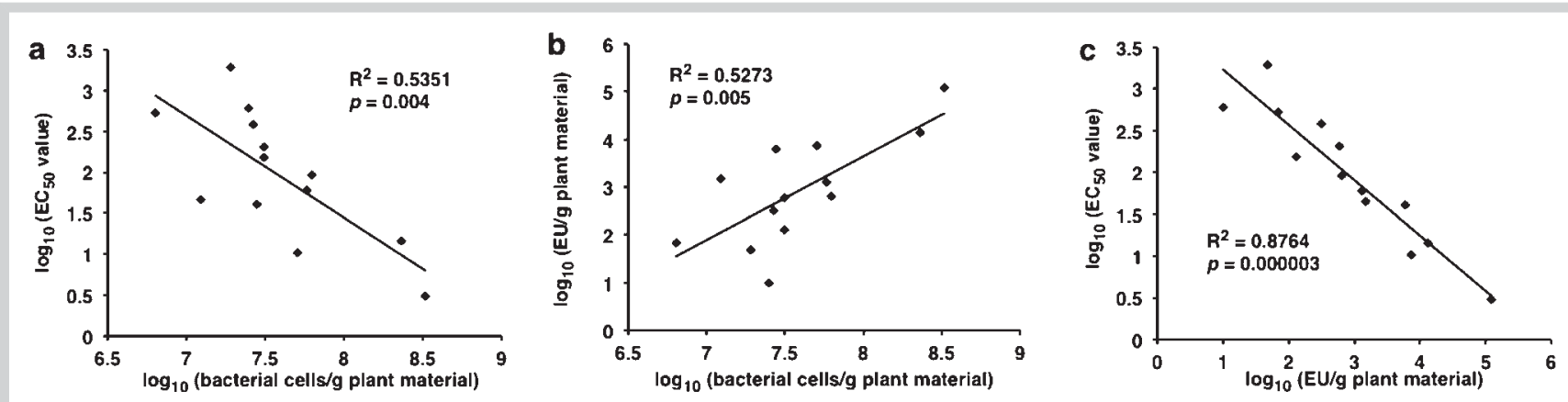

Fig. 2 Correlations between bacterial load, THP-1 monocyte stimulatory activity, and LPS levels in extracts from Echinacea. E. purpurea root and herb (aerial) plant parts were obtained as bulk raw material from six commercial growers (11 samples) and an individual plant cultivated at the University of Mississippi (herb and root). The plant material was extracted with 4\% SDS and the crude extracts were assessed for activity in THP-1 monocytes transfected with an NF-kB luciferase reporter plasmid ( $\mathrm{EC}_{50}$ values of extracts are expressed in $\mu \mathrm{g}$ of plant material $/ \mathrm{mL}$, ranging between 3 and 1940). The LPS content of each extract, expressed as EU/g of dried plant material (levels ranged between 10 and 121160), was determined using the Chromo-LAL assay with Glucashield ${ }^{\circledR}(1 \rightarrow 3)$ - $\beta$-D-glucan inhibiting buffer. The total bacterial load in dried plant samples was estimated as described in 0 Fig. 1. Relationships are shown as pairwise linear regressions between macrophage stimulatory extract activity and total bacterial load of plant material (a), extract LPS levels and total bacterial load of plant material (b), and macrophage stimulatory activity and LPS levels in plant extracts (c). Regression analyses were performed on $\log _{10}$ transformed data using Microsoft Excel 2007.

\section{Discussion}

$\nabla$

In the present study, we have developed a method to assess total bacterial load (culturable and nonculturable/nonviable bacteria) within both freshly harvested plants and commercially diverse dried bulk material. Using this method, we show that the activity (NF-KB activation in THP-1 cells) and content of LPS exhibited by Echinacea extracts is strongly correlated with the estimated total bacterial load of these plant samples.

In our initial experiments to estimate total bacterial load in Echinacea plant material, we used culture-dependent techniques. However, we found that less than $1 \%$ of the activity exhibited by extracts of the plant material was accounted for by the activity of extracts from the culturable bacteria (data not shown). This suggested that a culture-dependent method was problematic due to nonviable/nonculturable bacteria and/or potential cell loss during processing (filtering of homogenate before plating). Plant-derived immunostimulatory agents could not account for the observed discrepancy in activity since we have shown that the majority of the activity from this plant material is due to bacterial components [8]. Further experiments attempting to determine bacterial load using flow cytometry were also ineffective because of plant mitochondria interference (data not shown). Since molecular methods (PCR, qPCR) using standard universal bacterial primers are complicated by the coamplification of chloroplast and mitochondrial DNA, we developed a PCR quantification method using 16S rDNA primers that do not amplify chloroplast DNA. Bacterial PCR products are separated from mitochondrial products on agarose gels and the intensity of the bacterial band is then compared to band intensities of a standard curve using known bacterial numbers (PCR amplified using the same primers). This simple method has not been previously described and can be used to estimate total bacterial load in both dried and freshly harvested plant material ( $\bullet$ Fig. 1).

We have previously reported [4] that the LAL-determined LPS content of Echinacea extracts was correlated with in vitro macrophage stimulatory activity. In the present study, these extracts were reanalyzed using the Chromo-LAL test kit with Glucashield ${ }^{\circledR}$. Glucashield ${ }^{\circledR}$ reagent blocks the contribution of $(1 \rightarrow 3)$ -

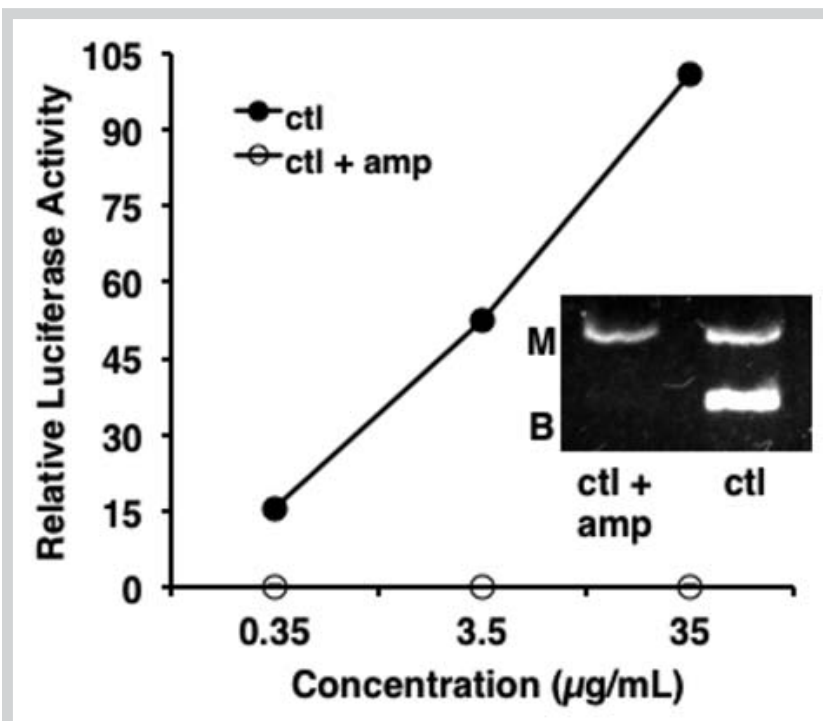

Fig. 3 Determination of total bacterial load and monocyte stimulatory activity of alfalfa sprouts treated with ampicillin during germination. Alfalfa seeds were surface sterilized and germinated in aseptic conditions in the presence (ctl + amp) or absence (ctl) of $30 \mu \mathrm{g} / \mathrm{mL}$ ampicillin for 7 days. Freeze-dried sprouts were extracted with $4 \%$ SDS at $98^{\circ} \mathrm{C}$ for $1 \mathrm{hr}$ and the extracts were assessed for activity in THP-1 monocytes transfected with an NF-KB luciferase reporter plasmid. Values are the average of duplicate determinations \pm range. Extracts of unsprouted alfalfa seeds exhibited undetectable activity at all concentrations tested (data not shown). Maximal inducing concentrations of LPS gives 100 RLA. (Insert) DNA was extracted from freeze-dried sprouts, amplified with bacterial 165 rDNA primers, and $P C R$ products were visualized on an agarose gel ("B" and " $M$ " signify bacterial and mitochondrial bands, respectively).

$\beta$-D-glucans in the LAL reaction. The use of this reagent is crucial during the analysis of plant extracts since trace levels of glucan are present from cellulosic material and from fungal/bacterial origin. When the Echinacea extracts were rerun in the presence of Glucashield ${ }^{\circledR}$, endotoxin units decreased by several folds for high LPS samples, whereas these values decreased by several or- 
ders of magnitude for samples with low levels of LPS. Regression analysis using these new endotoxin values resulted in a much stronger correlation ( $\nabla$ Fig. $\mathbf{2 c}$ ) between monocyte stimulatory activity and LPS content of Echinacea extracts.

Our previous research [8] demonstrated that the majority of the in vitro innate immune cell activation potential of Echinacea plant material was derived from bacterial Braun-type lipoproteins and LPS. Differences in the levels of these two bacterial components were also reported [4] to be responsible for the substantial variation (up to 200-fold) in activity from E. purpurea material sourced from six major growers/commercial suppliers in North America. On the basis of this data, we hypothesized that differences in bacterial content and/or bacterial type are responsible for the substantial variation observed in the macrophage activation potential exhibited by this plant material. In the current study, we show that the differences in total bacterial load between plant samples are strongly correlated with both the variation in activity ( Fig. $\mathbf{2 a}$ ) and the content of LPS ( $\bullet$ Fig. $\mathbf{2} \mathbf{b}$ ) within the extracts. However, the R-squared values (0.53 and 0.54 ) for these regressions indicate that total bacterial load does not fully account for the variation in content of LPS and activity. This suggests that additional factors, such as type of bacteria, are also important. We have begun to isolate and identify endophytic bacteria within freshly harvested plants and have preliminary data showing that there is substantial variation in the activity (more than 10000-fold) from extracts of different bacterial isolates (unpublished data). Future research is required to determine the extent that the type of bacteria in addition to its prevalence within E. purpurea contributes to this plant's immune-enhancing action. It is unlikely that plant-derived components contribute substantially to the observed variation in activity of the samples analyzed in the current study since we have previously shown that over $97 \%$ of the activity for in vitro macrophage activation exhibited by extracts of Echinacea was due to bacterial components [8].

In ways that are analogous to the commensal bacteria naturally associated with animals, most plants are colonized by bacterial endophytes that are typically present within vascular tissue and intercellular spaces $[12,13]$. These bacteria originate from soil around the roots or from the leaf surface $[13,14]$. The isolation of bacteria from virtually every plant studied suggests that it is likely that all plant species are colonized by endophytes [14]. Although it is our hypothesis that the bacterial load detected in E. purpurea plant material is predominantly from endophytes, it is possible that the high bacterial load detected in some of the commercial bulk plant material samples in 0 Fig. 2 could originate from postharvest events. However, we have previously reported [4] that different postharvest drying conditions do not significantly influence the content/activity of bacterial components within Echinacea plant samples. Furthermore, the current study indicates that it is possible to obtain a high bacterial load $\left(1.2 \times 10^{7}\right.$ and $3.1 \times 10^{7}$ bacterial cells/g of dried root and herb, respectively) from a plant harvested under controlled conditions at the University of Mississippi. This plant was washed extensively and then immediately freeze-dried to prevent postharvest growth or introduction of bacteria. Since washing removes most epiphytic bacteria (reviewed in [15]), it is likely that endophytes are predominantly responsible for the detected bacterial load in this plant material.

In agreement with our previous research [8], we show that ampicillin suppresses the appearance of activity (NF-KB activation of THP-1 cells) during the aseptic germination of alfalfa seeds. Fur- thermore, we show ( $\bullet$ Fig. 3 insert) that ampicillin treatment dramatically decreases total bacterial load in alfalfa sprouts during the 7-day germination period. These results demonstrate that endophytic bacteria, residing within the seeds, are able to proliferate (by over 100 times) during germination to give rise to the detected activity. The total bacterial load estimated in the germinated control alfalfa seeds is similar to the levels detected in some of the E. purpurea plant samples tested in $\bullet$ Fig. 2.

The current study, together with our previously published research $[4,8]$, provides strong evidence that bacteria within E. purpurea are a major source of immune-enhancing components (Braun-type lipoproteins and LPS) in this popular botanical. Cells of the innate immune system detect Braun-type lipoproteins and LPS through Toll-like receptor 2 (TLR2) and TLR4-dependent pathways, respectively [16]. Research from our lab and others have demonstrated that oral consumption of TLR2 and TLR4 agonists can impact immune parameters in animal and human clinical studies. Mice orally fed an extract from Spirulina platensis enriched for Braun-type lipoproteins exhibited augmented ex vivo production of IL- 6 and IgA from Peyer's patch cells and IFN- $\gamma$ from spleen cells [17]. In two separate human clinical trials, dietary supplementation with this extract for one week enhanced NK cell activity an average of 40 and 54\% [18]. Additional research by Akao et al. reported that oral consumption of a hot water Spirulina extract reduced tumor growth in mice through enhancement of NK cell activity via a TLR2- and TLR4-dependent process [19]. The high levels of TLR2 (Braun-type lipoproteins) and TLR4 (LPS) agonists in Echinacea may contribute to the therapeutic action of this plant material. For example, these bacterial components may explain the enhanced NK cell activity observed in mice by dietary administration of Echinacea $[6,20]$.

Oral ingestion of Echinacea plant material containing a high bacterial load may have effects similar to those reported in studies using probiotic bacteria. A recent study using human subjects evaluated the in vivo intestinal mucosal gene expression profile six hours after oral administration of heat-killed Lactobacillus plantarum [21]. Ingestion of dead bacteria was found to induce gene expression mainly involved in innate and adaptive immune responses. These effects may be most pertinent to the potential effect of bacteria within Echinacea since the majority of bacteria within dried plant material are nonviable.

The average bacterial load within the Echinacea plant material evaluated in this study is comparable to the daily therapeutic dose of live bacteria used in studies evaluating the effect of probiotics on disease resistance. We found that the average bacterial load in E. purpurea was $7 \times 10^{7}$ bacterial cells/g of dried plant material. Consuming a typical recommended dose [22] of 2.7-3.0 g Echinacea plant material/day, containing this average bacterial load would result in a daily dose of about $2 \times 10^{8}$ bacterial cells. This bacterial load within Echinacea is comparable to the daily dose of probiotics (between $5 \times 10^{7}$ and $2 \times 10^{10} \mathrm{CFU}$ ) that have been used in studies reporting statistically significant effects on various parameters related to the common cold and flu infections (reviewed in [23]). For example, a recent double blind, placebocontrolled study on the consumption of probiotics in 326 children (3-5yrs old) reported statistically significant reductions over placebo during a six-month period with respect to incidence of fever (73\%), coughing (62\%), rhinorrhea (59\%), and antibiotic use (84\%) [24]. Additional research is required to evaluate whether the bacteria associated with Echinacea plant material can impart similar therapeutic effects on colds and flu infections 
to that observed in studies using oral consumption of live probiotics.

\section{Acknowledgements}

This research was partly funded by Grant Number R01AT007042 from the National Center for Complementary and Alternative Medicines (NCCAM) and the Office of Dietary Supplements (ODS). The contents of this manuscript are solely the responsibility of the authors and do not necessarily represent the official views of the NCCAM, ODS, or the National Institutes of Health. Additional funding of this research was also provided by a grant from the USDA, Agricultural Research Service Specific Cooperative Agreement Nos. 58-6408-6-067 and 58-6408-1-603.

\section{Conflict of Interest}

$\nabla$

All authors declare that there are no conflicts of interest.

\section{References}

1 Woelkart $K$, Linde $K$, Bauer R. Echinacea for preventing and treating the common cold. Planta Med 2008; 74: 633-637

2 Chen Y, Fu T, Tao T, Yang J, Chang Y, Wang M, Kim L, Qu L, Cassady J, Scal$z o R$, Wang $X$. Macrophage activating effects of new alkamides from the roots of Echinacea species. J Nat Prod 2005; 68: 773-776

3 Raduner S, Majewska A, Chen Z, Xie XQ Hamon J, Faller B, Altmann KH, Gertsch J. Alkylamides from Echinacea are a new class of cannabinomimetics. Cannabinoid type 2 receptor-dependent and -independent immunomodulatory effects. J Biol Chem 2006; 281: 14192-14206

4 Tamta H, Pugh ND, Balachandran P, Moraes R, Sumiyanto J, Pasco DS. Variability in in vitro macrophage activation by commercially diverse bulk Echinacea plant material is predominantly due to bacterial lipoproteins and lipopolysaccharides. J Agric Food Chem 2008; 56: 10552-10556

5 Raso GM, Pacilio M, Di Carlo G, Esposito E, Pinto L, Meli R. In-vivo and invitro anti-inflammatory effect of Echinacea purpurea and Hypericum perforatum. J Pharm Pharmacol 2002; 54: 1379-1383

6 Brousseau M, Miller SC. Enhancement of natural killer cells and increased survival of aging mice fed daily Echinacea root extract from youth. Biogerontology 2005; 6: 157-163

7 Pugh ND, Balachandran P, Lata H, Dayan FE, Joshi V, Bedir E, Makino T, Moraes R, Khan I, Pasco DS. Melanin: dietary mucosal immune modulator from Echinacea and other botanical supplements. Int Immunopharmacol 2005; 5: 637-647

8 Pugh ND, Tamta H, Balachandran P, Wu X, Howell J, Dayan FE, Pasco DS. The majority of in vitro macrophage activation exhibited by extracts of some immune enhancing botanicals is due to bacterial lipoproteins and lipopolysaccharides. Int Immunopharmacol 2008; 8: 1023-1032

9 Pugh N, Ross SA, ElSohly MA, Pasco DS. Characterization of Aloeride, a new high-molecular-weight polysaccharide from Aloe vera with potent immunostimulatory activity. J Agric Food Chem 2001; 49: 1030-1034

10 Chelius MK, Triplett EW. The diversity of archaea and bacteria in association with the root of Zea mays L. Microb Ecol 2001; 41: 252-263

$11 \mathrm{McDonald} J \mathrm{H}$. Handbook of biological statistics, 2nd edition. Baltimore, MD: Sparky House Publishing; 2009

12 Sturz AV, Christie BR, Nowak J. Bacterial endophytes: potential role in developing sustainable systems of crop production. Crit Rev Plant Sci 2000; 19: $1-30$

13 Rosenblueth M, Martínez-Romero E. Bacterial endophytes and their interactions with hosts. Mol Plant Microbe Interact 2006; 19: 827-837

14 Ryan RP, Germaine K, Franks A, Ryan DJ, Dowling DN. Bacterial endophytes: recent developments and applications. FEMS Microbiol Lett 2008; 278: 1-9

15 Hirano SS, Upper CD. Bacteria in the leaf ecosystem with emphasis on Pseudomonas syringae-a pathogen, ice nucleus, and epiphyte. Microbiol Mol Biol Rev 2000; 64: 624-653

16 Kawai T, Akira S. The role of pattern-recognition receptors in innate immunity: update on Toll-like receptors. Nat Immunol 2010; 11: 373384

17 Balachandran P, Pugh ND, Ma G, Pasco DS. Toll-like receptor 2-dependent activation of monocytes by Spirulina polysaccharide and its immune enhancing action in mice. Int Immunopharmacol 2006; 6: 1808-1814

18 Nielsen CH, Balachandran P, Christensen O, Pugh ND, Tamta H, Sufka KJ, Wu X, Walsted A, Schjørring-Thyssen M, Enevold C, Pasco DS. Enhancement of natural killer cell activity in healthy subjects by Immuli$\mathrm{na}^{\circledR}$, a Spirulina extract enriched for Braun-type lipoproteins. Planta Med 2010; 76: 1802-1808

19 AkaoY, Ebihara T, Masuda H, Saeki Y, Akazawa T, Hazeki K, Hazeki O, Matsumoto M, Seya T. Enhancement of antitumor natural killer cell activation by orally administered Spirulina extract in mice. Cancer Sci 2009; 100: 1494-1501

20 Delorme D, Miller SC. Dietary consumption of Echinacea by mice afflicted with autoimmune (type I) diabetes: effect of consuming the herb on hemopoietic and immune cell dynamics. Autoimmunity 2005; 38: 453-461

21 van Baarlen P, Troost FJ, van Hemert S, van $\operatorname{der}$ Meer C, de Vos WM, de Groot PJ, Hooiveld GJ, Brummer RJ, Kleerebezem M. Differential NF-KB pathways induction by Lactobacillus plantarum in the duodenum of healthy humans correlating with immune tolerance. Proc Natl Acad Sci USA 2009; 106: 2371-2376

22 Garrard J, Harms S, Eberly LE, Matiak A. Variations in product choices of frequently purchased herbs: caveat emptor. Arch Intern Med 2003; 163: 2290-2295

23 Weichselbaum E. Probiotics and health: a review of the evidence. BNF Nutr Bull 2009; 34: 340-373

24 Leyer GJ, Li S, Mubasher ME, Reifer C, Ouwehand AC. Probiotic effects on cold and influenza-like symptom incidence and duration in children. Pediatrics 2009; 124: e172-e179 